\title{
Statistical Estimations of the Distribution of Fire Growth Factor - Study on Risk-Based Evacuation Safety Design Method
}

\author{
YOSHIKAZU DEGUCHI ${ }^{1}$, HIROAKI NOTAKE ${ }^{2}$, JUN'ICHI YAMAGUCHI ${ }^{3}$, and TAKEYOSHI \\ TANAKA $^{4}$ \\ ${ }^{1}$ Research \& Development Institute \\ Takenaka Corporation \\ 1-5-1 Ohtsuka, Inzai-city, Chiba, 270-1395, Japan \\ ${ }^{2}$ Institute of Technology \\ Shimizu Corporation \\ 3-4-17 Etchujima, Koto-ku, Tokyo, 135-8530, Japan \\ ${ }^{3}$ Technical Research Institute \\ Obayashi Corporation \\ 4-640, Shimokiyoto, Kiyose-city, Tokyo, 204-8558, Japan \\ ${ }^{4}$ Disaster Prevention Research Institute \\ Kyoto University \\ Gokasyo, Uji, Kyoto, 611-0011, Japan
}

\begin{abstract}
In performance-based evacuation safety design methods at present, consideration of fire risk has been insufficient. In order to develop the framework of performance-based evacuation safety verification, the authors have proposed a methodology for selecting both design fire scenarios and design fires based on the fire risk in fire, which we call the Risk-Based Evacuation Safety Design Method.

In the Risk-Based Evacuation Safety Design Method the fire growth factor $\alpha$ and its distribution $f(\alpha)$ is one of the key points. We analyze the data of fire growth time $(t)$ and burned area $\left(A_{f}\right)$ in the national fire statistics in Japan to obtain distributions of fire growth factor in real fire situations in terms of burned area. Then we estimate a heat release rate per unit floor area using the existing fire load density survey and burn experiments. The distributions of fire growth factor $f(\alpha)$ are obtained by multiplying the burned area growth factor $\left(A_{f} f t^{2}\right)$ and the heat release rate per unit floor area $\left(q^{\prime \prime}\right)$.

It is found that the distributions of the fire growth factor $f(\alpha)$ follows a log-normal distribution and that the fire growth factors from the existing experiments are within a reasonable range of the distributions.
\end{abstract}

KEYWORDS: risk-based design, fire growth factor, fire growth time, burned area, burned area growth factor, heat release rate per unit floor area.

\section{NOMENCLATURE LISTING}

$\begin{array}{llll}A_{f} & \text { burned area }\left(\mathrm{m}^{2}\right) & \alpha & \text { fire growth factor }\left(\mathrm{kW} / \mathrm{s}^{2}\right) \\ C & \text { causality (person) } & \alpha_{c} & \text { limit fire growth factor }\left(\mathrm{kW} / \mathrm{s}^{2}\right) \\ C_{0} & \text { initial number of occupants (person) } & \mu & \text { mean } \\ D & \text { diameter of fire source }(\mathrm{m}) & \sigma & \text { standard deviation } \\ H & \text { flame height }(\mathrm{m}) & \lambda & \text { mean of } \mathrm{L}-\mathrm{N} \text { distribution } \\ P & \text { probability of loss by fire } & \zeta & \text { standard deviation of L-N distribution } \\ Q & \text { heat release rate }(\mathrm{kW}) & \text { subscripts } \\ R & \text { evacuation safety failure risk } & A & \text { acceptable } \\ W & \text { fire load density }\left(\mathrm{kg} / \mathrm{m}^{2}\right) & D & \text { design } \\ q^{\prime \prime} & \text { heat release rate per unit floor area }\left(\mathrm{kW} / \mathrm{m}^{2}\right) & f & \text { start spraying } \\ q^{\prime \prime}{ }_{s} & \text { heat release rate per unit surface area }\left(\mathrm{kW} / \mathrm{m}^{2}\right) & i & \text { scenario number } \\ t & \text { time }(\mathrm{s}) & \max & \text { maximum } \\ \text { Greek } & s & \text { start of fire }\end{array}$




\section{INTRODUCTION}

In Japan, performance-based codes have been introduced by the amendment of the Building Standard Law in 2000 to provide more flexibility and clarity in the building regulatory system. However, the consideration of fire risk has scarcely integrated. In the performance-based verification method, we use uniform fire growth factors and criteria regardless of the size of spaces and occupants. This has caused unbalanced practices in fire safety verification, such as that it is more difficult to verify the safety of small rooms with insignificant numbers of occupants than the safety of whole building with a large number of occupants. On the other hand, risk consideration is thought to be integrated into the existing prescribed code even though it is implicit and empirical. The fire safety standards for large buildings and buildings accommodating unspecified members of the public are implicitly more severe than the standards for other buildings. In order to develop a sound framework for performance-based evacuation safety verification, the authors proposed a methodology for selecting both design fire scenarios and design fires based on fire risk, which we call the Risk-Based Evacuation Safety Design Method [1-5] but the frequency distribution of the fire growth factor used was only an assumption.

In this paper, we analyze fire reports collected by the National Fire Defense Agency for fire statistics [6] to obtain the frequency distribution of the fire growth factor $\alpha$, The frequency distributions were obtained for building uses of office, residence, restaurant and merchandise store.

\section{CONCEPT OF RISK-BASED EVACUATION SAFETY DESIGN METHOD}

\section{Procedure of Fire Safety Verification}

The Risk-Based Evacuation Safety Design Method is assumed to be conducted as the usual performancebased evacuation safety design method procedure as illustrated in Fig. 1, in which evacuation safety is verified by deterministic manner, where the fire conditions predicted under the selected design fires and fire scenarios are compared with prescribed safety criteria.

The other important features of the current performance-based fire safety design methods to be taken into account in the Risk-Based Evacuation Safety Design Method are:

- Assumed fires are always hazardous fires, disregarding trivial fires such as smoldering fires,

- Number of evacuees in a space is calculated assuming the space is fully loaded by occupants,

- Safety criteria is set at strict level, such as 'not exposed' or 'only slightly exposed' to smoke,

- Safety verification, including calculation methods used, is to be made conservative enough.

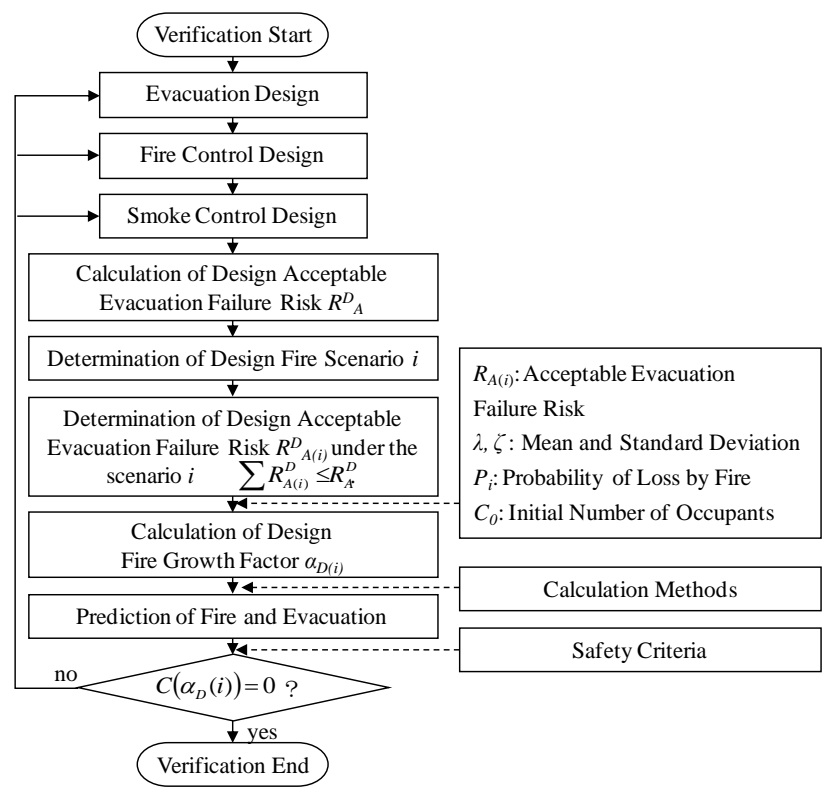

Fig. 1. Procedure of Risk-Based Evacuation Safety Design Method. 


\section{Relationship between Design Fire and Fire Growth Factor}

Generally, the fire growth factor $\alpha$ depends on a variety of factors, such as, the type and intensity of ignition source, size and material properties of ignited item and so on. Therefore, the growth factor of a fire which starts in a building space, where various combustibles exist together cannot be constant but can vary at random.

This risk-based design method considers that the fire growth factor $\alpha$ follows a probability density function $f(\alpha)$ which is set according to building use. Besides, because of targeting on floor evacuation safety, at the initial stage of fire, the heat release rate (HRR) of the fire source is assumed to increase in proportion to time-squared ( $t^{2}$ fire) and becomes constant after it reaches the maximum HRR, as in many other evacuation safety verification methods at present [7].

The maximum HRR is controlled by ventilation conditions, sprinkler installation etc. and is assumed to be constant although, in reality, it may vary depending on the various conditions involved.

\section{Relationship between Acceptable Evacuation Failure Risk and Fire Growth Factor}

Figure 2 shows a relationship between the acceptable evacuation failure risk and fire growth factor in the context of the Risk-Based Evacuation Safety Design Method.

Generally, the number of causalities to occur depends on the magnitude of the fire growth factor $\alpha$. Figure 2 (top left) shows a concept of the relationship between fire growth factor $\alpha$ and causalities caused $C(\alpha)$. Causalities will be zero when the fire growth factor $\alpha$ is very small but will begin to increase when the fire growth factor $\alpha$ exceeds a certain limit fire growth factor $\alpha_{c}$ and it becomes constant at $C_{0}$ when $\alpha$ further increases. It is too difficult, or impossible in nature, to know how $C(\alpha)$ increases in the range of $\alpha>$ $\alpha_{c}$, because it depends on many conditions related with evacuation safety. However, since causalities $C(\alpha)$ cannot exceed the initial occupant load but a fire with the limit fire growth factor $\alpha_{c}$ may become large. That is, $C(\alpha)=C_{0}\left(\alpha>\alpha_{c}\right)$ is a conservative evaluation. Therefore, the design evacuation risk $R^{D}(i)$ is described as Eq. 1 under the fire scenario $i$, letting $P_{i}$ be probability of loss of fire.

$R^{D}(i) \leq P_{i} C_{0} \int_{\alpha_{c}}^{\infty} f(\alpha) d \alpha$

A design goal of the Risk-Based Evacuation Safety Design Method is to control the evacuation risk under an acceptable risk level, i.e., $R^{D}<R_{A}{ }^{D}$. Therefore, for an evacuation safety plan to be acceptable, reading the critical fire growth factor $\alpha_{c}$ in Eq. 1as the design fire growth factor $\alpha_{D}$, it is necessary to design the spaces and safety systems to allow all the occupants to evacuate safely under the fire with $\alpha\left(0<\alpha<\alpha_{D}\right)$.

$P_{i} C_{0} \int_{\alpha_{D}}^{\infty} f(\alpha) d \alpha \leq R_{A}^{D}(i)$

In other words, the evacuation safety can be accomplished by the design that allows no casualties to occur $(C(\alpha)=0)$ under the design fire $Q=\alpha_{D} t^{2}$, which can be obtained by solving.

$$
\int_{\alpha_{D}}^{\infty} f(\alpha) d \alpha=\frac{R_{A}^{D}(i)}{P_{i} C_{0}}
$$




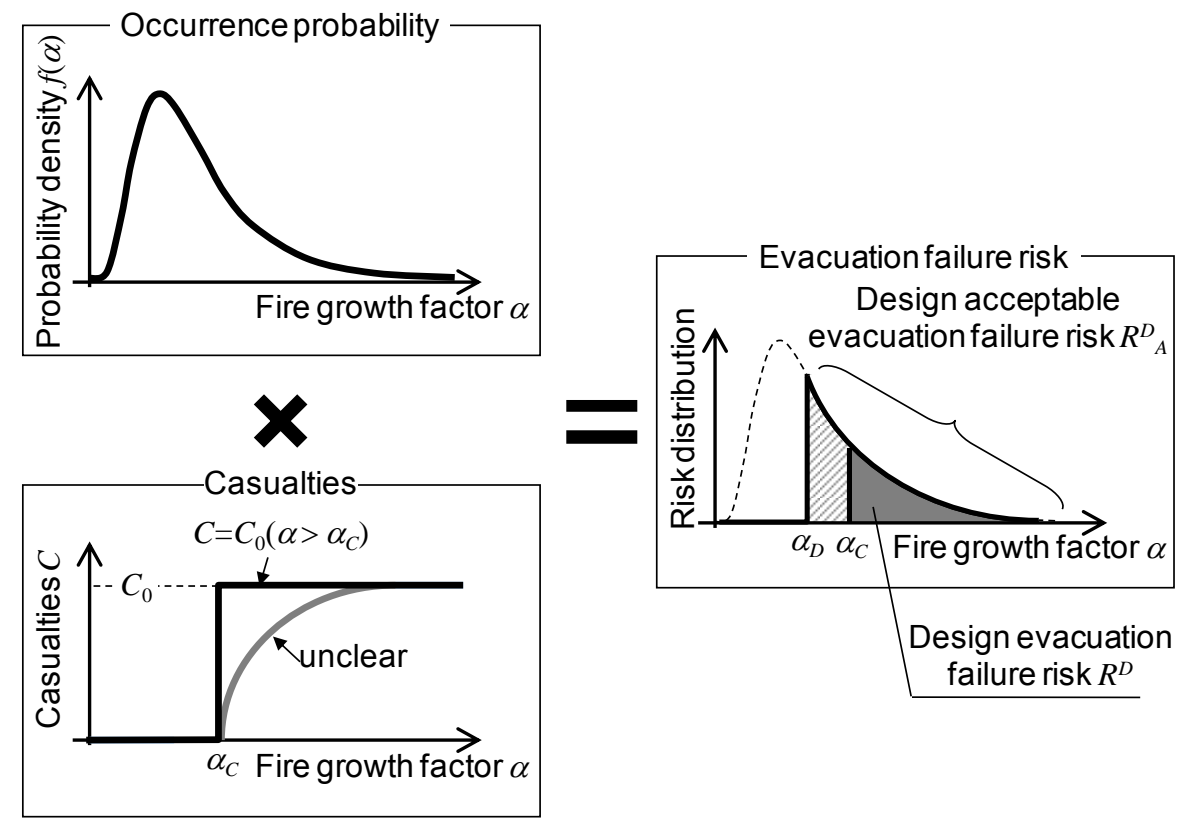

Fig. 2. Relationship between acceptable evacuation failure risk and fire growth factor.

\section{ESTIMATION METHOD OF THE DISTRIBUTION OF FIRE GROWTH FACTOR}

\section{Fire Growth Factor in Verification Method of Evacuation in Japan}

Since oxygen consumption calorimetric technology was invented, burning characteristics of various items have been measured and their fire growth factors have been obtained. However, it is still not known what items and how frequently they are ignited in real fire situations. In performance-based fire safety design practices, the fire growth factor of design fires is selected based on expert discretion, often from NFPA's fast, medium, slow fires.

In Japanese procedure for evacuation safety design, Calculation method etc. for the verification method for floor Evacuation safety [7], the fire growth factor $\alpha$ is correlated with the calorific fire load density $\left(q_{l}\right)$ as follows,

$\alpha=\left\{\begin{array}{cc}0.0125 & \left(q_{l} \leq 170\right) \\ 2.6 \times 10^{-6} q_{l}^{5 / 3} & \left(q_{l}>170\right)\end{array}\right.$

Equation 4 is based on a model which takes into account the ideal conditions that homogeneous combustibles are uniformly distributed in a space. Although this formula is actually used in the current verification of evacuation safety of buildings, the basic assumption of Eq. 4 is not necessarily reasonable enough to be defensible. However, more preferably, the fire growth factor $\alpha$ is estimated with fire statistics which represent actual fire conditions.

\section{Calculation Method for the Fire Growth Factor Based on Fire Statistics}

Fire statistics reflects real fire situations better than burn experiments but, needless to say, limitations exist to in using fire statistics to obtain the fire growth factor $\alpha$. Firstly, HRR is not measured in real fire, so we need to be satisfied with obtaining burned area instead. Therefore HRR per unit burned area have to be estimated by some other means. In this paper, considering the formula as below, we obtain the fire growth factor in terms of burned area, $A_{f}$, from fire reports, and HRR per unit burned area $q^{\prime \prime}$ from fire load density survey and burn experiments separately, and obtain the fire growth factor $\alpha$ by multiplying these two. 
The same method for obtaining fire growth factor using burned area from fire statistics was applied by Charters et al. to limited occupancy [8,9].

$\alpha=\frac{Q_{f}}{\left(t_{f}-t_{s}\right)^{2}}=q^{\prime \prime} \cdot \frac{A_{f}}{t^{2}}$

where, $Q_{f}$ is the HRR at start of water spraying time $(\mathrm{kW}), q^{\prime \prime}$ is the HRR per $\mathrm{m}^{2}\left(\mathrm{~kW} / \mathrm{m}^{2}\right), A_{f}$ is the burned area $\left(\mathrm{m}^{2}\right), t_{f}$ is the start of water spraying time $(\mathrm{s}), t_{s}$ is the ignition time $(\mathrm{s})$ and $t=t_{f}-t_{s}$.

\section{ESTIMATION OF THE DISTRIBUTION OF BURNED AREA GROWTH FACTOR BASED ON FIRE STATISTICS}

\section{Fire Statistics Data}

The data used in this paper to analyze the burn area growth factor are the fire reports submitted to the National Fire Defense Agency for national fire statistics. Of these, we extracted the fire reports of the buildings with uses office, residence, restaurant and merchandise store considering the amount of data available for the analyses. The data were limited focusing on the initial stage of fire considering that the purpose of the survey is to analyze the initial fire growth factor. Also, a small number of extremely fast developing fires, due to explosion and the like, are excluded.

The attributes of the data extracted from the fire reports are as follows:

- year; 1995-2008,

- number of damaged buildings; 1 ,

- $\quad$ burned area; more than $1 \mathrm{~m}^{2}$,

- first aid fire fighting; none,

- time from start spraying to suppression ; less than $60 \mathrm{~min}$,

- time from break out to start spraying ; less than 20 min,

- burned area is under $90 \%$ of floor area of fire origin,

- building use on fire; office, residence, restaurant, merchandise store,

- $\quad$ exclude fire growth factor $\alpha$ is over 1 .

\section{Treatment of Fire Statistics Data}

Figure 3 illustrates the method of handling the fire report data to calculate the fire growth factor $\alpha$. The dashed line shows the image of growth of burned area $A_{f}$ in actual fire and the solid line shows the image of approximated fire growth curve. The symbol, $\star$ stands for the data that is available from the fire report.

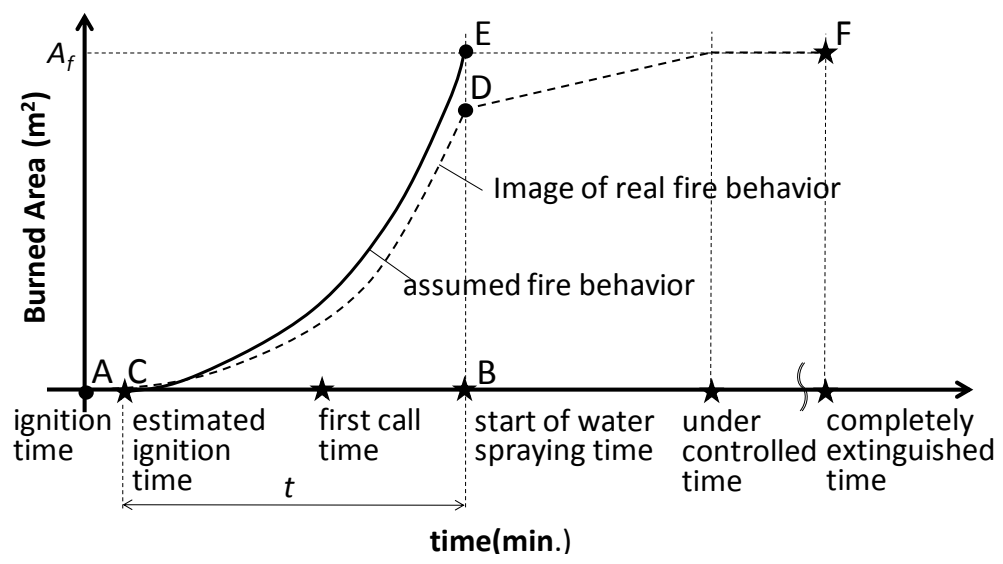

Fig. 3. Image of treatment of fire statistics. 
The fire ignition time $(\mathrm{C})$ was estimated by the fire department. Although a certain degree of error may be involved between the true values (A), we trust the accuracy of the professional estimate by the fire department. While the start of water spraying time (B) must be almost accurate, we cannot obtain the burned area at that time (D). Alternately, we replace the time (B) with that of the final burned area (F). Assuming that the fire spread was negligible after the start of water spraying because we focus the early fire stage, so that the burned area at the start water spraying (E) is not greatly different from the burned area at the time of extinguishment $(\mathrm{F})$.

\section{Analysis of Extracted Data}

Fire prevention measures are classified into four categories, 'single use', 'multiple uses', 'small scale' and 'others'. Figure 4 shows the fire prevention measures categories by each building use. Figure 5 shows the categories of causes of fire and Fig 6 shows the categories of fire source. The important features are:

- In the case of office, 'Cigarettes' and 'Arson' have a high proportion in causes of fire and 'Fibers Combustibles' and 'Wastes' have a high proportion in fire source excluding 'unknown'.

- In the case of residence, 'Cigarettes' has a high proportion of causes of fire and 'Fibers Combustibles' accounts for $40 \%$.

- In the case of restaurant, causes of fire are variety, although 'Cook appliances' have a high proportion compared with other building uses and 'Inflammable Liquid' has high proportion in fire source compared with other building uses.

- In the case of merchandise store, causes of fire are similar to that of restaurant and 'Solid Combustibles' has a high proportion in fire source compared with other building uses.

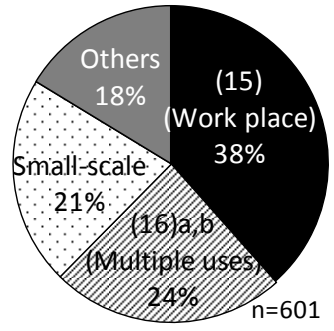

(a)

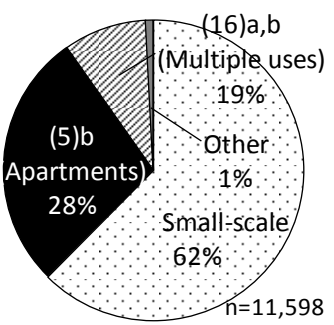

(b)

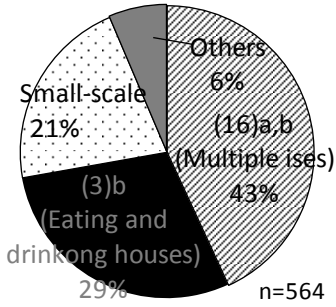

(c)

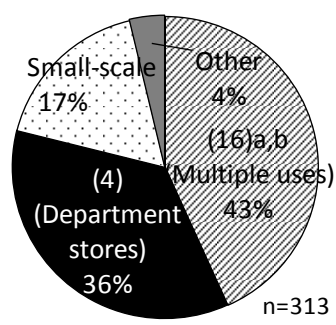

(d)

Fig. 4. Categories of building use by fire prevention measures: (a) office; (b) residence; (c) restaurant; (d) merchandise store.

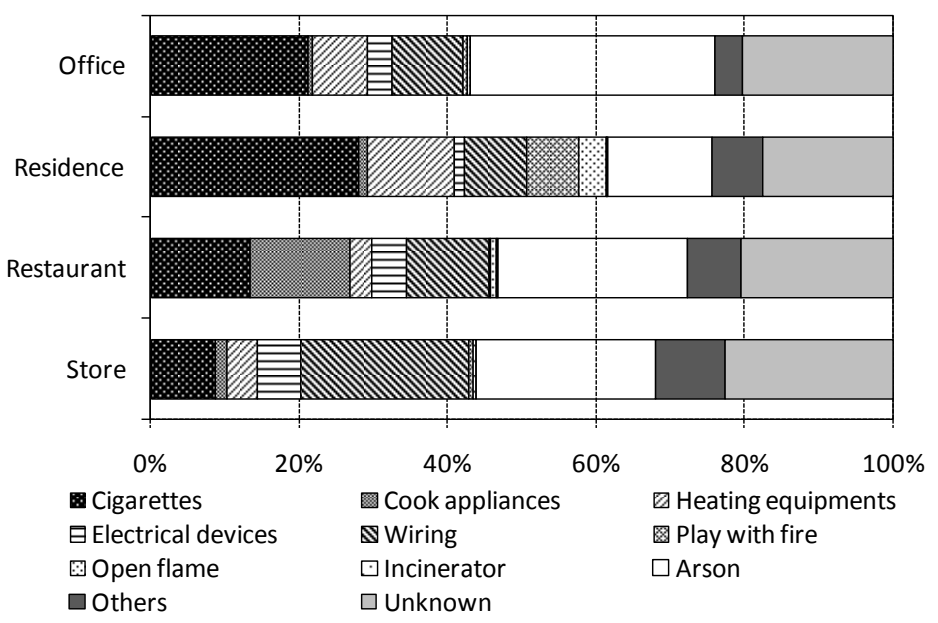

Fig. 5. Categories of causes of fire. 


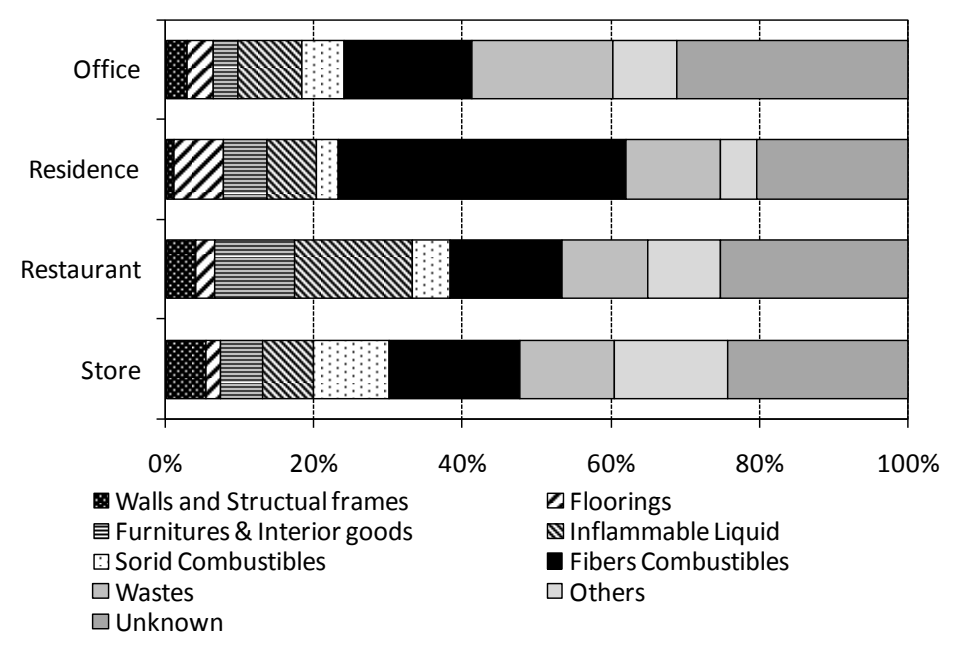

Fig. 6. Categories of fire source.

\section{Distribution of Start of Water Spraying Time}

Figure 7 shows the relative frequency of the time from ignition to start of water spraying $t$. As Fig. 7 indicates, the mean $\mu$ (12.9-13.2) and standard deviation $\sigma$ (3.7-4.0) of start of water spraying time $t$ are similar with each building use.

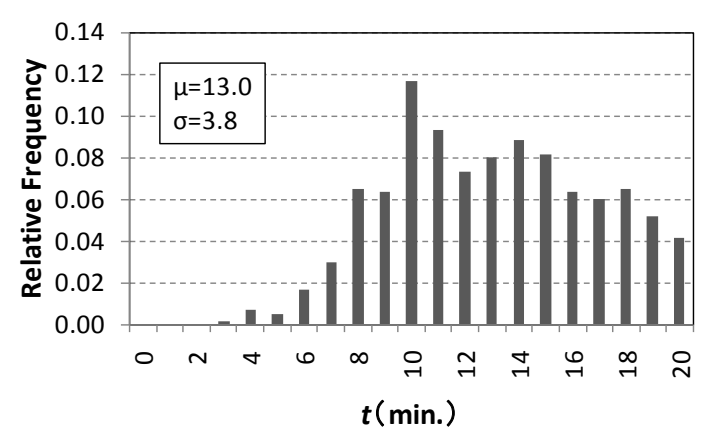

(a)

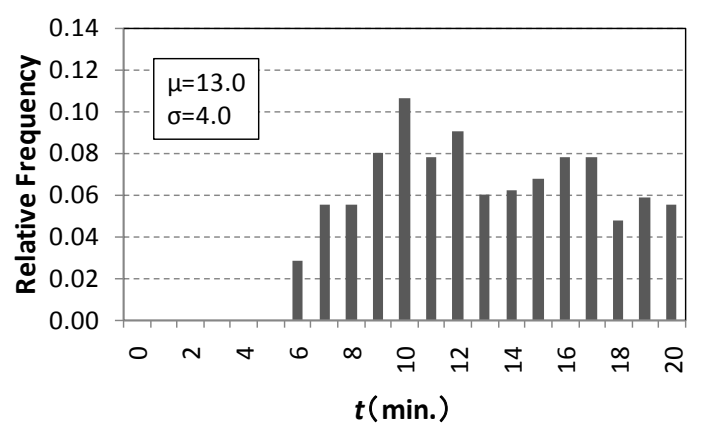

(c)

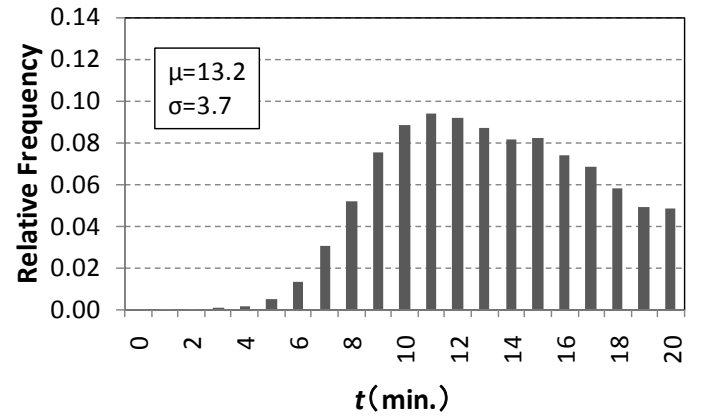

(b)

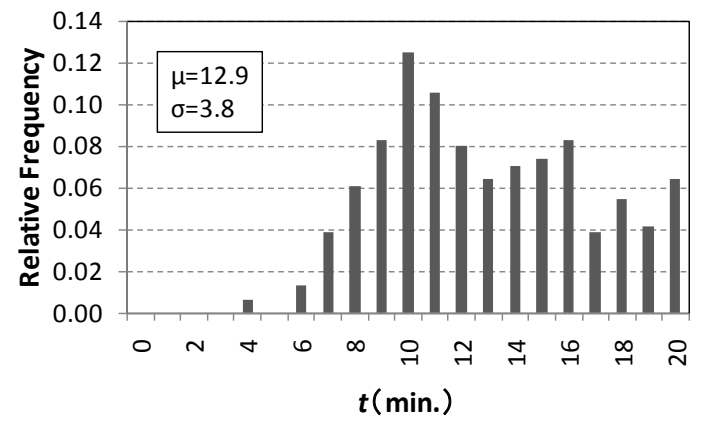

(d)

Fig. 7. Relative frequency of start of water spraying time $t$ : (a) office; (b) residence; (c) restaurant; (d) merchandise store. 


\section{Distribution of Burned Area}

Figure 8 shows the relative frequency of burned area $A_{f}$. As Fig. 8 indicates, the mean burned area $\mu$ of residence and merchandise store are larger than the others. However, the frequency distributions are similar for all the types of use.

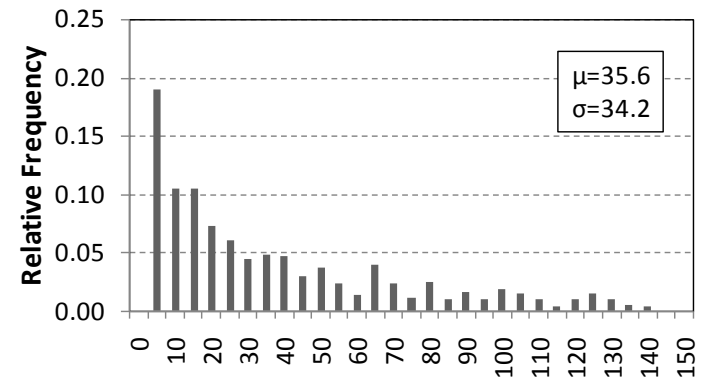

$A_{f}\left(\mathrm{~m}^{2}\right)$

(a)

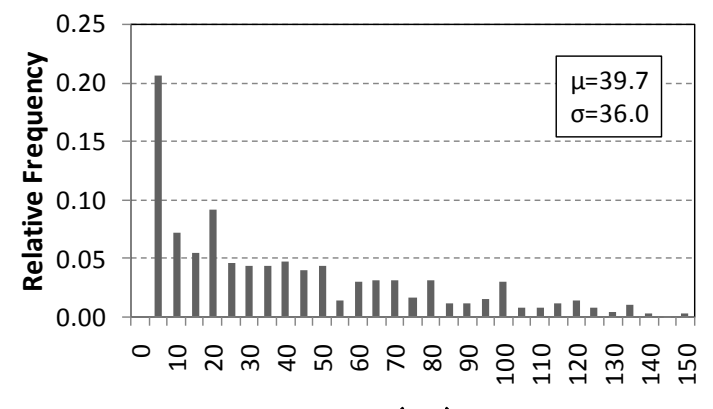

$A_{f}\left(m^{2}\right)$

(c)

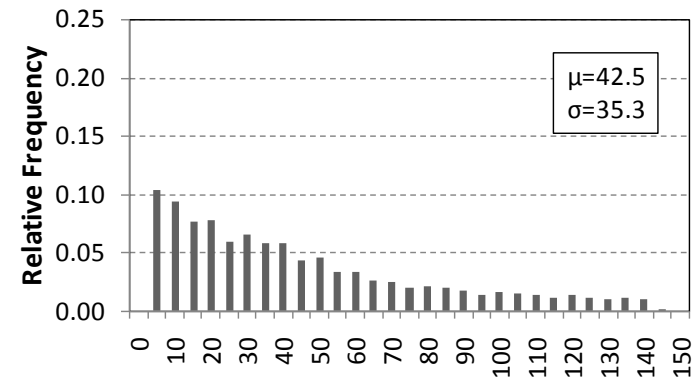

$A_{f}\left(m^{2}\right)$

(b)

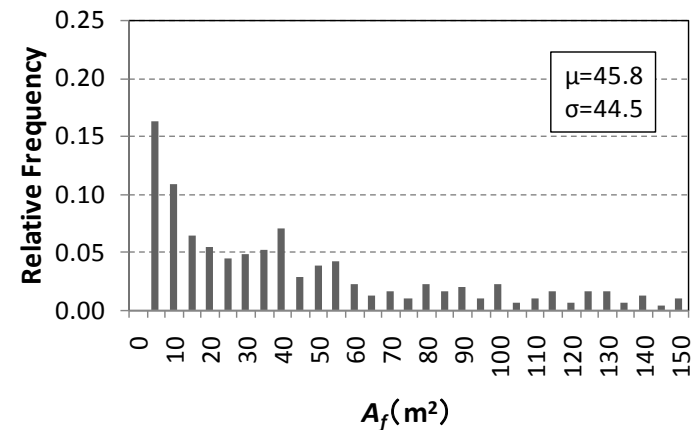

(d)

Fig. 8. Relative frequency of burned area $A_{f}$ : (a) office; (b) residence; (c) restaurant; (d) merchandise store.

\section{Distribution of Burned Area Growth Factor}

The burned area growth factors $A_{f} / t^{2}$ were obtained and statistically processed. Table 1 shows the statistics: mean $\mu$, standard deviation $\sigma, \log$-normal distribution's mean $\lambda$ and standard deviation $\xi$, defined by Eq. 6 and 7. Figure 9 illustrates the relative frequency from the fire statistics and the log-normal distribution function shown in Table 1.

$$
\begin{aligned}
& g(\alpha)=\frac{1}{\sqrt{2 \pi} \zeta \alpha} \exp \left(\frac{-(\log \alpha-\lambda)}{2 \zeta^{2}}\right) \\
& \lambda=\ln \mu-\frac{1}{2} \zeta^{2}, \quad \zeta^{2}=\ln \left(1+\frac{\sigma^{2}}{\mu^{2}}\right)
\end{aligned}
$$

From Table 1 and Fig. 9, the building uses do not make much difference in the mean $\mu$ and standard deviation $\sigma$. However, restaurant is the smallest and merchandise store is the largest mean and standard deviation, although causes of fire are similar in restaurant and merchandise store, as we noted in the analysis of Fig. 5. This tendency may be attributed to the fact that only somewhat limited types of combustibles (not causes of fire and fire source) tend to exist in a restaurant relative to a merchandise store where more variety of combustibles exists. 
In all building uses, the data of fire statistics is larger than the assumed log-normal distributions in the range of $5.0 \times 10^{-5}$. In other words, the statistics include the fires which spread more slowly than the assumed log-normal distribution. This means it is more conservative to use the assumed log-normal distribution in the evacuation verification. Therefore, the frequency distribution of the burned area growth factor $A_{f} / t^{2}$ can be modeled as a log-normal distribution.

Table 1. Statistics of burned area growth factor.

\begin{tabular}{|l|c|c|c|c|c|}
\hline \multicolumn{1}{|c|}{ Building use } & Office & Residence & Restaurant & Store \\
\hline Number & 601 & 11,598 & 564 & 313 \\
\hline \multicolumn{7}{|c|}{ Burned area growth factor $A_{f} / t^{2}\left(\times 10^{-5} \mathrm{~m} / \mathrm{s}^{2}\right)$} \\
\hline mean & $\mu$ & 7.6 & 8.1 & 7.4 & 9.7 \\
\hline standard deviation & $\sigma$ & 11.0 & 9.3 & 7.8 & 12.2 \\
\hline minimum & 0.077 & 0.069 & 0.077 & 0.069 \\
\hline 75 percentile & 3.9 & 5.4 & 5.0 & 5.3 \\
\hline 90 percentile & 9.4 & 10.4 & 10.2 & 12.3 \\
\hline 95 percentile & 18.3 & 17.4 & 17.0 & 22.6 \\
\hline 99 percentile & 57.2 & 45.4 & 37.3 & 59.5 \\
\hline maximum & 224.0 & 131.1 & 45.3 & 70.9 \\
\hline $\begin{array}{l}\text { log-normal } \\
\text { distribution }\end{array}$ & $\lambda$ & -9.15 & -10.85 & -9.89 & -9.72 \\
\cline { 2 - 6 } & $\xi$ & 1.19 & 0.92 & 0.87 & 0.97 \\
\hline
\end{tabular}

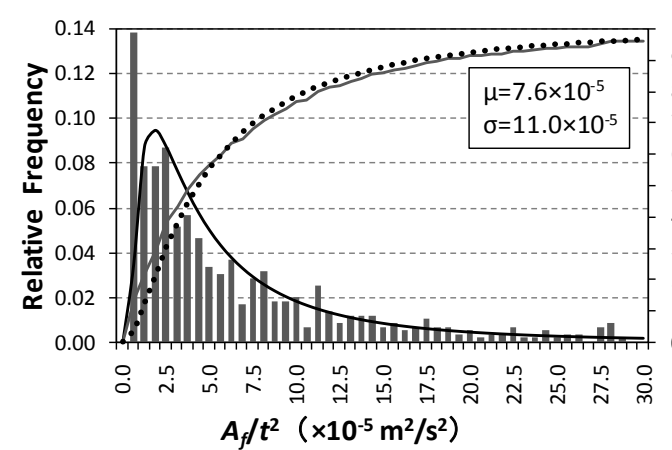

(a)

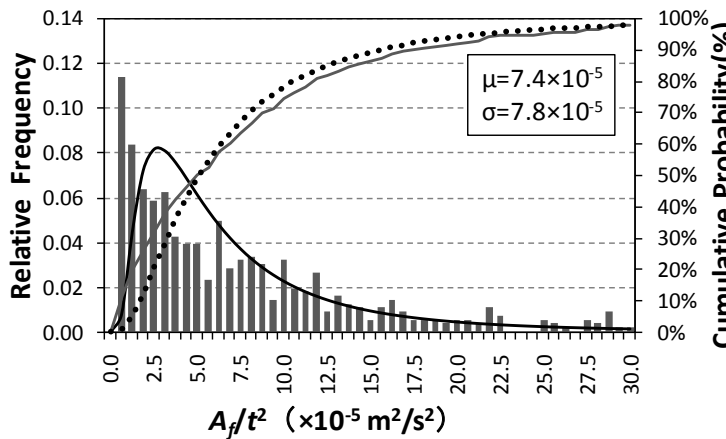

(c)

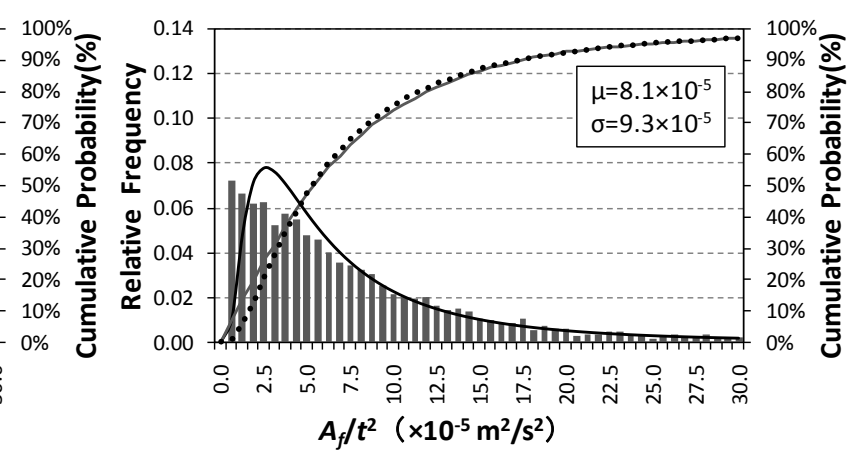

(b)

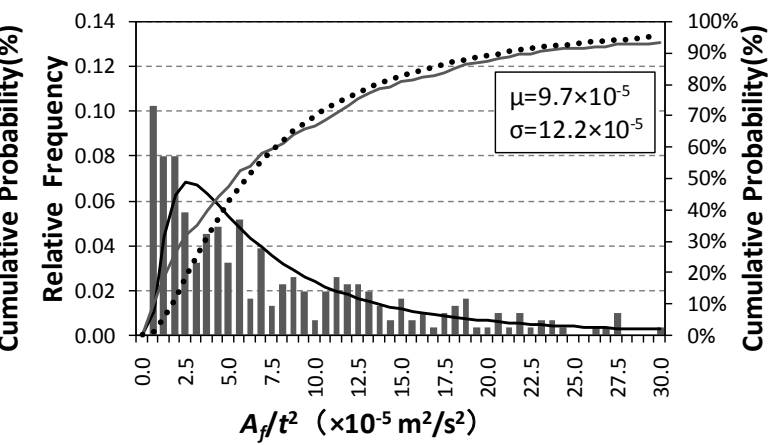

(d)

Fig. 9. Frequency distribution of burn area growth factor $A_{f} / t^{2}$ : (a) office; (b) residence; (c) restaurant; (d) merchandise store. 


\section{ESTIMATION OF THE HEAT RELEASE RATE PER UNIT FLOOR AREA}

\section{Estimation Method}

As described above, it is necessary to know the HRR per unit floor area $q^{\prime \prime}$ to obtain the fire growth factor $\alpha\left(\mathrm{kW} / \mathrm{s}^{2}\right)$. The $q^{\prime \prime}$ is influenced by the combustible conditions. In this paper, the following two methods are tentatively proposed serves as examples to estimate $q^{\prime \prime}$ :

- $\quad$ EXAMPLE 1: Estimation from combustible survey

- $\quad$ EXAMPLE 2: Estimation from burn experiments

However, there may be more accurate estimation methods depending on the availability of relevant data.

\section{EXAMPLE 1: Estimation from Combustible Survey}

Kurioka et al. [10] have investigated combustible distribution, fire load and combustible surface area in standard office buildings. Equation 8 shows the relationship between the effective surface area $\Phi_{\text {eff }}$ and the fire load density $W$. In this paper, it is reported that the effective surface area $\Phi_{\text {eff, is proportional to }}$ the $-2 / 3^{\text {rd }}$ power of the fire load density $W$, which converts synthetic high flammability polymers into a wood equivalent in terms of calorific value. Table 2 shows the fire load density $W$ in this survey.

$\Phi_{e f f}=0.70 \cdot W^{-2 / 3}$

where, $\Phi_{\text {eff }}$ is the effective surface area $\left(\mathrm{m}^{2}[\mathrm{fuel}] / \mathrm{kg}\right), W$ is the fire load density which is the converted synthetic high flammability polymer into wood $\left(\mathrm{kg} / \mathrm{m}^{2}[\right.$ floor $\left.]\right)$.

Table 2. Results on fire load density survey.

\begin{tabular}{|c|c|c|}
\hline \multirow{2}{*}{ Building use } & \multicolumn{2}{|c|}{ Fire load density $\boldsymbol{W}\left(\mathbf{k g} / \mathbf{m}^{\mathbf{2}}\right)$} \\
\cline { 2 - 3 } & range & mean \\
\hline Clerical desk unit & $22.4-52.0$ & 38.9 \\
\hline Engineering desk unit & $43.3-82.8$ & 65.6 \\
\hline
\end{tabular}

Here, assuming the heat release rate of fire source $Q$ can be related to the combustible surface area, $q^{\prime \prime}$ can be given as a function of the fire load density $W$ as Eq. 9.

$q^{\prime \prime}=q_{s}^{\prime \prime} \cdot \Phi_{e f f} \cdot W=0.70 \cdot q_{s}^{\prime \prime} \cdot W^{1 / 3}$

where, $q_{s}{ }^{\prime \prime}$ is the heat release rate per unit fuel surface area $\left(\mathrm{kW} / \mathrm{m}^{2}[\right.$ fuel] $)$.

According to the existing test data, the HRR per unit fuel surface area of wood based fuel $q^{\prime \prime}$ ranges from 48-112 $\left(\mathrm{kW} / \mathrm{m}^{2}\right)$. Here we adopt $112 \mathrm{~kW} / \mathrm{m}^{2}$ as a conservative estimation. From Eq. 9 and Table 2, the required $q^{\prime \prime}$ can be obtained from Table 3 . If the fire load density $W$ is already known, it will be convenient to use this method.

Table 3. Estimated HRR per $\mathrm{m}^{2}$ based on fire load density survey.

\begin{tabular}{|c|c|c|}
\hline \multirow{2}{*}{ Building use } & \multicolumn{2}{|c|}{$\begin{array}{r}\text { Heat release rate per } \mathbf{~ m}^{\mathbf{2}} \\
\mathbf{q}^{\prime \prime}\left(\mathbf{k W} / \mathbf{m}^{\mathbf{2}}\right)\end{array}$} \\
\cline { 2 - 3 } & range & mean \\
\hline Clerical desk unit & $218.7-288.0$ & 262.4 \\
\hline Engineering desk unit & $271.9-336.7$ & 311.8 \\
\hline
\end{tabular}




\section{EXAMPLE 2: Estimation from Burn Experiments}

In order to obtain $q^{\prime \prime}$ from burn experiments, the values of both heat release rate $Q$ and burned area $A_{f}$ have to be measured. However, information for burned area $A_{f}$ is rarely available in almost all of experiments performed in the past. In this paper, a value of $q^{\prime \prime}$ is obtained from the results of a previous burn experiments known as the Kuramae fire experiment [11], which includes information on the burned area $A_{f}$. The heat release rate $Q$ is calculated from the flame height measured in the experiment.

The Kuramae fire experiment was conducted at the old Sumo Arena by the Tokyo Fire Department to investigate the smoke layer filling behavior and the performance of fire detectors for use in firefighting.

Assuming a merchandise store in a large compartment with a high ceiling, $600 \mathrm{~kg}$ of hanged cloths was arranged in a $20 \mathrm{~m}^{2}$ area, i.e. $30 \mathrm{~kg} / \mathrm{m}^{2}$, as fuel, and ignited at the center by using $100 \mathrm{cc}$ of methanol.

\section{Calculation of HRR per Unit Floor Area $q$ ”}

Figure 10 shows the burning properties: weight loss, burned area and the flame height, measured in the Kuramae experiment. From Fig. 10, 7 min after ignition, the fire has reached a peak HRR, at which the burned area $A_{f}$ was $20 \mathrm{~m}^{2}$ and the flame height $H$ was $12 \mathrm{~m}$. We estimate the heat release rate $Q$ using Eq. 10 for flame height:

$H=3.5\left(\frac{Q}{1116 \cdot D^{5 / 2}}\right)^{2 / 3} \times D$

where, $H$ is flame height (m) and $D$ is diameter of fire source (m).

Substituting $H=12 \mathrm{~m}, D=\sqrt{ } 20 \mathrm{~m}$ into Eq. 10, the peak heat release rate $Q_{\max }$ was found to be $31.7 \mathrm{MW}$, and the HRR per unit floor area $q$ " is calculated to be $1,585 \mathrm{~kW} / \mathrm{m}^{2}$ as shown below.

$q=\frac{Q}{A_{f}}=\frac{31,700}{20}=1,585$

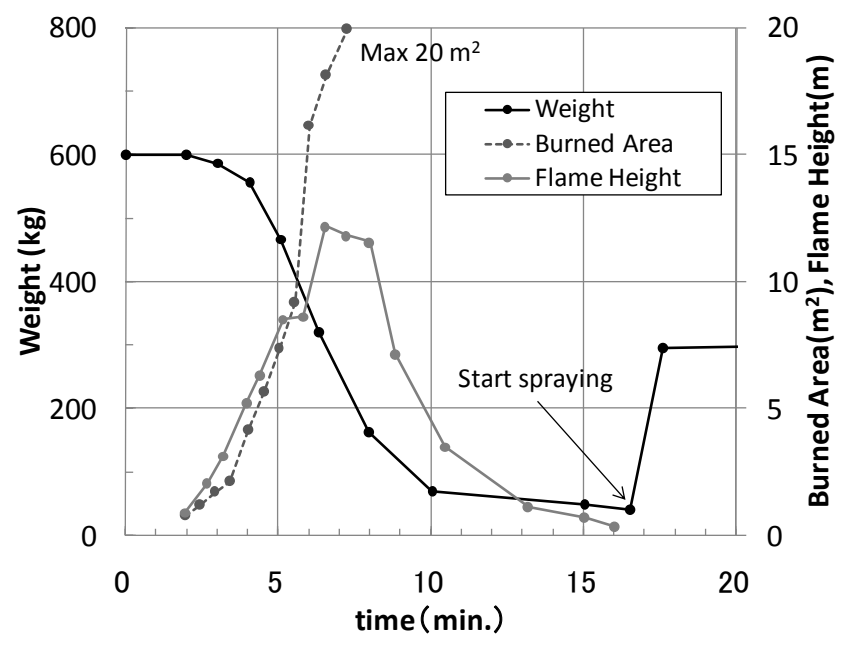

Fig. 10. Measured burn properties in Kuramae fire experiment [11]. 


\section{CALCULATION OF DISTRIBUTION OF FIRE GROWTH FACTOR}

The fire growth factor distribution $f(\alpha)$ is given by multiplying $q^{\prime \prime}$ and the distribution of burned area growth factor $g(\alpha)$ from Eq. 12 .

$f(\alpha)=q^{\prime \prime} \times g(\alpha)$

where, $g(\alpha)$ is the probability density of the burned area growth factor $A_{f} f t^{2}$ demonstrated in Fig. 9.

The HRR per unit floor areas $q^{\prime \prime}$, are shown in Table 4. In an engineering office case, the value is $311.8 \mathrm{~kW} / \mathrm{m}^{2}$. Although the relationship between the effective surface area $\Phi_{\text {eff }}$ and the fire load density $W$ as described in Eq. 8 could not be acquired for general building uses except office, we regard that Eq. 8 applys to other type of use and estimate $q^{\prime \prime}$ using the calorific load density prescribed in Calculation method etc. for the verification method for floor Evacuation safety.

Table 4. Assumed fire load density and estimated HRR per unit floor area.

\begin{tabular}{|c|c|c|}
\hline Building use & $\begin{array}{c}\text { Fire load } \\
\text { density } \boldsymbol{W}\left(\mathbf{k g} / \mathbf{m}^{\mathbf{2}}\right)\end{array}$ & $\begin{array}{c}\text { HRR per } \mathbf{~}^{\mathbf{2}} \\
\boldsymbol{q}^{\mathbf{\prime}}\left(\mathbf{k W} / \mathbf{m}^{\mathbf{2}}\right)\end{array}$ \\
\hline Office & 65.6 & 311.8 \\
\hline Residence & 45.0 & 278.9 \\
\hline Restaurant & 30.0 & 243.6 \\
\hline Merchandise store & 30.0 & 243.6 \\
\hline
\end{tabular}

The results of the calculation using the $q^{\prime \prime}$ in Table 4 are shown in Fig. 11. In addition, the fire growth factor for merchandise store is also calculated using experimentally obtained $q^{\prime \prime}$ in Fig. 12.

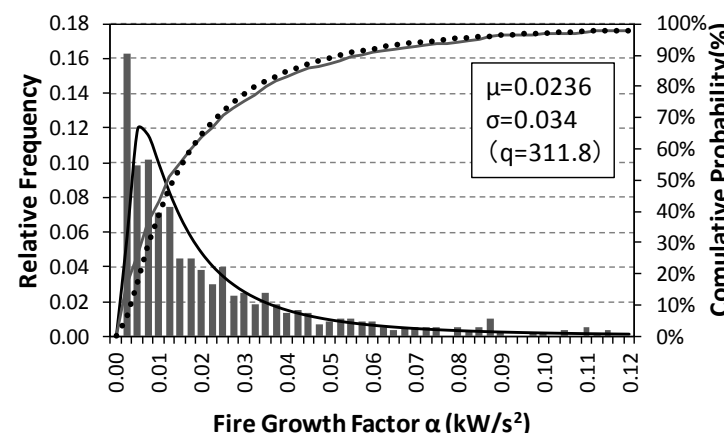

(a)

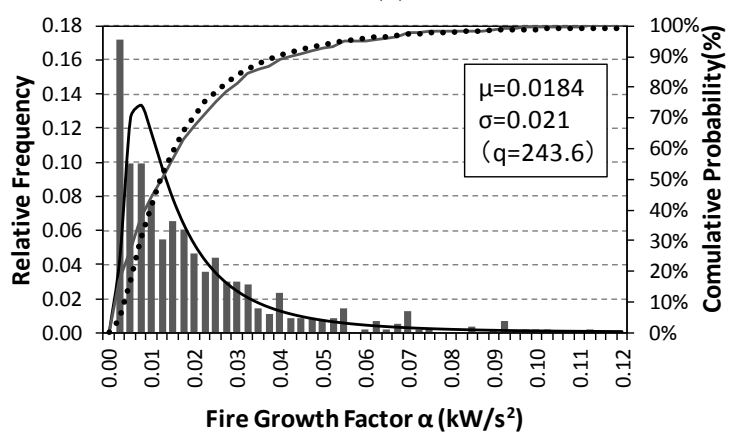

(c)

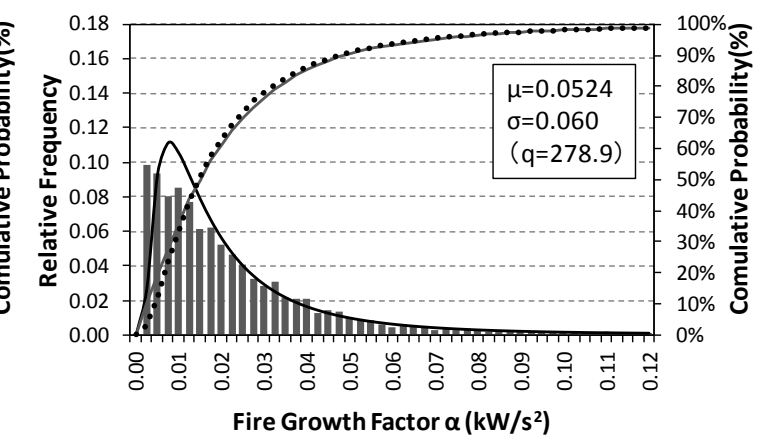

(b)

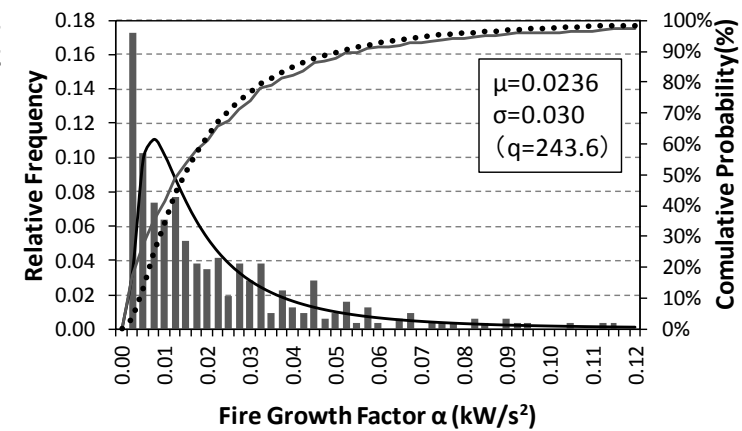

(d)

Fig. 11. Frequency distribution of fire growth factor $\alpha$ : (a) office; (b) residence; (c) restaurant; (d) merchandise store. 


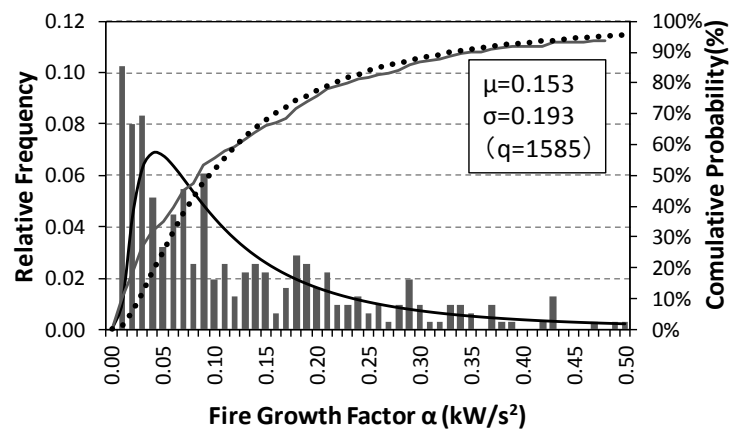

Fig. 12. Frequency distribution of fire growth factor $\alpha$ using experimentally obtained $q^{\prime \prime}$.

In conjunction with the introduction of the performance-based evaluation method of fire service equipment into the Fire Service Law, a series of experiments for the investigation of the performance of sprinkler system were conducted [12]. Three kinds of fire source (small; watch/jewel store, middle; toy store, large; furniture store) were set up in the experiment. The fire growth factors estimated from the experiments are shown in Table 5.

The mean value of the fire growth factor for office $\mu=0.0236 \mathrm{~kW} / \mathrm{s}^{2}$ in Fig. 11 is within the range of 0.02 to $0.05 \mathrm{~kW} / \mathrm{s}^{2}$ in Table 5 . However the value of store use, $0.0236 \mathrm{~kW} / \mathrm{s}^{2}$, is much less than the values for the experiment in Table 5. On the other hand, as shown in Fig. 12, the value of store use established with the experimentally obtained $q^{\prime \prime}$ is $0.153 \mathrm{~kW} / \mathrm{s}^{2}$, that is between the value of watch/jewel store $\left(0.0776 \mathrm{~kW} / \mathrm{s}^{2}\right)$ and toy store $\left(0.2129 \mathrm{~kW} / \mathrm{s}^{2}\right)$, which may be reasonable if small items burn more frequently than large items in real fires. However, it may be necessary to use the distribution in Fig. 12 for shops selling cloths and big furniture stores for conservative treatment.

Needless to say, direct comparison between the statistically obtained and experimentally obtained fire growth factors is difficult. In real fires, a variety items can burn in an unintended manner while selected items are intentionally burned in experiments. Therefore the comparison here is just to confirm the agreement at an order of magnitude for the fire growth factors.

Table 5. Experimental result of fire growth factor [12].

\begin{tabular}{|c|l|c|}
\hline Building use & \multicolumn{2}{|c|}{ Fire growth factor $\boldsymbol{\alpha}\left(\mathbf{k W} / \mathbf{s}^{\mathbf{2}}\right)$} \\
\hline Office & \multicolumn{2}{|c|}{$0.02-0.05$} \\
\hline \multirow{3}{*}{ Merchandise store } & (small; watch/jewel) & 0.0776 \\
\cline { 2 - 3 } & (middle; toy) & 0.2129 \\
\cline { 2 - 3 } & (large; furniture) & 0.4210 \\
\hline
\end{tabular}

\section{CONCLUSION}

In order to develop the framework for the Risk-Based Evacuation Safety Design Method the authors have proposed a methodology for selecting both design fire scenarios and design fires based on fire risk.

In the Risk-Based Evacuation Safety Design Method, the fire growth factors $\alpha$ and their distribution $f(\alpha)$ is among the key points. Firstly we obtained the fire growth factors in terms of burn area by analyzing the fire reports submitted for national fire statistics. Secondly, we estimated heat release rate per unit floor area $\left(q^{\prime \prime}\right)$ and burned area growth factor $\left(A_{f} / t^{2}\right)$.

It is found that the estimated frequency distribution of the fire growth factor $\alpha$ approximately follows the curve of a log-normal distribution. In future, it may be necessary to further improve the selection of heat release rate per unit floor area $q^{\prime \prime}$ to estimate the distribution of fire growth factor more accurately. 


\section{REFERENCES}

[1] Tanaka, T. and Yamaguchi, J., "Selection of Design Fires in Evacuation Safety Designs of Buildings based on Fire Risk Concept," Proceedings of the Seventh Asia-Oceania Symposium on Fire Science and Technology, 2007.

[2] Tanaka, T. (2009) Risk-based Selection of Design Fires to ensure an Acceptable Level of Evacuation Safety, Fire safety Science 9: 49-61, http://dx.doi.org/10.3801/IAFSS.FSS.9-49

[3] Ikehata, Y., Notake, H., Yamaguchi, J., and Tanaka, T. "Analysis of Fire Statistics for Establishing Benchmark Fire Risk for Evacuation Safety Designs of Buildings," Proceedings of the Eighth International Conference on Performance-Based Codes and Fire Safety Design Methods, 2010, pp.85-96.

[4] Nii, D., Yamaguchi, J., Notake, H., Yuka Ikehata, and Tanaka, T. "Risk-based Selection of Design Fire Scenarios in Performance based Evacuation Safety Designs of Buildings", Proceedings of the Eighth International Conference on Performance-Based Codes and Fire Safety Design Methods, 2010, pp.97-108.

[5] Tanaka, T., Nii, D., Yamaguchi, J., Ikehata, Y., and Notake, H. "A Study on Risk-based Evacuation Safety Design Method for Office Buildings", The Interflam 2010 Proceedings of the Twelfth International Conference, 2010.

[6] Tokyo Hourei Ltd., Handbook of Fire Statistics, 2007. (in Japanese)

[7] The Building Center of Japan, Japanese Verification Methods for Determining Safe Evacuation of a Floor and Building, Kaibundo, 2005, p.55. (in Japanese)

[8] Charters, D.A., Mcgrail, D., Fajemirokun, N., Want, Y., Townsend, N. and Holborn, P.G.,(2003) Preliminary Analysis of the Number of Occupants, Fire Growth, Detection Times and Premovement Times for Probabilistic Risk Assessment, Fire Safety Science 7: 357-368. http://dx.doi.org/10.3801/IAFSS.FSS.7-357

[9] Holborn, P.G., Nolan, P.F., and Golt, J. (2004) An Analysis of Fire Sizes, Fire Growth Rates and Times between Events using Data from Fire Investigations, Fire Safety Journal, 39(6): 481-524. http://dx.doi.org/10.1016/j.firesaf.2004.05.002

[10] Kurioka, H., Sato, H., Yashiro, Y., Kakegawa, S., Kasahara, I., Ikehata, Y., Wakamatsu, T. and Matsuyama, K. "Result of Fire Load Investigation - A study on Design Fires for Means of Egress in Office Building Part 1,” Building Institute Japan , 2002, p.197-198. (in Japanese)

[11] Tokyo Fire Dep., Report of Fire Experiments in Kuramae Sumo Amphitheater, 1985, p.65. (in Japanese)

[12] Fire and Disaster Management Agency, Review Meeting Report of the State of General Fire Prevention Safety Evaluation Standard of the Fire Prevention Buildings, 2005 (in Japanese) 